\title{
Trayectorias migratorias. Entre trayectorias directas, azarosas y nómades*
}

\author{
Migratory trajectory. Direct, azarous and nomads trajectory
}

Yasna Contreras ${ }^{\mathrm{a}}$

Historial del artículo Recibido:

13 de diciembre de 2019.

Aceptado:

26 de diciembre de 2019 a Departamento de Geografía, Universidad de Chile, Santiago, Chile. Correo electrónico: ycontrerasg@uchilefau.cl

* Resultados derivados del Fondecyt Regular 1171722 "Geografías del acceso a la vivienda para inmigrantes latinoamericanos y del Caribe" y entrevistas realizadas en el marco del proyecto VID Enlace ENL04/16. Agradezco a la geógrafa y estudiante del Magíster en Geografía de FAU, Beatriz Seguel la construcción de las figuras aquí presentadas y el apoyo en el análisis de entrevistas.

\section{Palabras clave}

Inmigrante, migrante, movilidad, trayectoria

\section{Keywords}

Immigrant, migrant, mobility, trajectory

\section{Resumen}

Históricamente los territorios se han configurado a partir del arribo de sujetos y familias de diferentes orígenes cuyas tradicionales causas de movilidad están asociadas a la búsqueda de empleo y/o mejores expectativas de vida, contemplando trayectorias migratorias que aluden a espacios de origen y destino. Este artículo reflexiona sobre el concepto trayectoria migratoria y se cuestiona cómo se construye la trayectoria y cuáles son las estrategias y arbitrajes a los que recurre el/la sujeto (a) migrante. Se postula que la trayectoria migratoria comprende la articulación de todos los nodos que explican la salida de un lugar, el tránsito por otro y la permanencia. La trayectoria rompe con la tradicional idea de que sujetos migrantes salen de un destino y llegan a otro de supuesta acogida. La condición de acogida es puesta en tensión en dos sentidos: muchas de las trayectorias no coinciden con los proyectos originales de los sujetos, más bien, habitan actualmente en territorios que fueron parte de negociaciones en ruta y, en segundo lugar, algunas/os son sometidos a discursos y prácticas racistas lo que cuestiona el término acogida. La discusión se plantea desde el análisis de diez entrevistas en profundidad realizadas a inmigrantes latinoamericanos y del Caribe que residen en el norte chileno. Se analizan las decisiones detrás de cada movimiento; las estrategias que despliegan; y el sentido que asignan a cada nodo que compone su trayectoria migratoria. El análisis permitió la construcción de tres tipos de trayectorias definidas aquí como directa, azarosa y nómade. Desde estas aproximaciones se concluye sobre la necesidad de plantear una crítica a la política migratoria, en tanto, debe reconocer la condición en la que arriba un sujeto; la racialización con la que carga, e incluso, las violencias a las que se ven expuestas durante su ruta al no ser considerados sujetos de derecho.

\footnotetext{
Abstract

Historically, the territories have been configured from the arrival of subjects and families of different origins whose traditional causes of mobility are associated with the search for employment and / or better life expectations, contemplating migratory trajectories that allude to spaces of origin and destination. This article reflects on the concept of migratory trajectory and questions how the trajectory is constructed and what are the strategies to which the migrant subject resorts. It is postulated that the migratory trajectory includes the articulation of all the nodes that explain the exit of one place, the transit through another and the place of arrival. The trajectory breaks with the traditional idea that migrant subjects leave a place of destination and arrive at another of supposed reception. The reception condition is put in tension in two ways: many of the trajectories do not coincide with the original projects of the subjects, rather, they currently live in territories that were part of negotiations on the road, and secondly, some are subjected to racist speeches and practices which questions the term host. The discussion arises from the analysis of ten in-depth interviews conducted with Latin American and Caribbean immigrants residing in northern Chile. The decisions behind each movement are analyzed; the strategies and the sense that they assign to each node that composes their migratory trajectory. The specified analysis is the construction of three types of trajectories defined here as direct, azarous and nomadic. From these approaches, the need to raise a critique of immigration policy is considered, while recognizing the condition in which a subject arrives; the racialization with the load, and even, the violence to which they are exposed during their route since they are not certain subjects of law Keywords: immigrant, migrant, mobility, trajectory.
} 


\section{Introducción}

Parte de las investigaciones sobre migración han identificado las rutas y dinámicas de dicho proceso, reconociendo que existen sociedades de acogida y otras de destino. Dos elementos exigen una reflexión. En primer lugar, cuestionarse si detrás de cada movimiento los sujetos migrantes tienen un proyecto o, más bien, salir de un determinado territorio es parte de una estrategia que se construye en ruta y que está medida por las condiciones de salida, por el origen, los estereotipos, las condiciones económicas, el ciclo de vida, el género, entre otras múltiples dimensiones que existen cuestionar que hay detrás de un supuesto proyecto migratorio. En segundo lugar, y con menor tiempo para debatirlo aquí, es necesario controvertir cuál es la supuesta acogida de territorios indistintamente su escala.

Bajo un marco de consolidación de Chile como uno de los países de mayor atracción migratoria dentro de la región latinoamericana, Andina y del Caribe, el artículo aspira a contribuir en una compresión espaciotemporal y social tras el término trayectoria, en tanto es un concepto que advierte las negociaciones y estrategias a las que debe recurrir un sujeto, ya sea hombre, mujer, con o sin hijos, de determinado origen, etnia y clase. También la trayectoria migratoria exige complejizar los movimientos de los sujetos en marcos cargados de racismo y violencia, ya sea en sus espacios de origen, entre los territorios en los que se movilizan y en países que imaginan acogedores.

Chile alberga aproximadamente 1,25 millones de migrantes lo que representa casi el $4 \%$ de la población a nivel nacional. Los últimos datos del Censo 2017, evidencian que el colectivo de mayor aumento corresponde a migrantes venezolanos ( $23 \%$ del total), seguido por la población haitiana que comprende aproximadamente el $14 \%$ de los migrantes residentes en el país. Más que detenerse en las cifras, resulta significativo analizar desde ellas la distribución concentrada de migrantes en diferentes territorios. Si bien Santiago como capital sigue siendo la que concentra el mayor número de población, emergen Maule, Ñuble y O'Higgins como espacios de nueva atracción migratoria (Departamento de Extranjería [DEM], 2019), lo que exigen nuevas investigaciones.

La dispersión concentrada de la migración a nivel país llevar a discutir cuáles son las relaciones que se producen entre tradicionales territorios de atracción migratoria (metrópolis de Santiago y ciudades intermedias como Antofagasta, Iquique, Valparaíso, entre otras), y nuevos espacios. No es azaroso el recorrido al interior del país realizado por un migrante o inmigrante. La oferta laboral, el rol de redes sociales y familiares, los contactos que tejen en ruta, las condiciones de habitabilidad; la relación entre el nivel de ingreso, tipo de contrato y vivienda a la que pueden acceder (Contreras, Neville \& González, 2019), entre otros factores, explican en cierta medida por qué encontramos inmigrantes en diferentes territorios rurales y urbanos de Chile.

Indagar sobre la construcción de trayectorias migratorias puede advertir, además, las violencias a las que se ven sometidas muchos y muchas inmigrantes. Se apela al término inmigrante, en tanto parte de los entrevistados (as) con los que coproducimos conocimiento se ven sometidos cotidianamente a connotaciones negativas "relacionadas con la desnaturalización del otro mediante la figura del extranjero, del que se encuentra fuera los límites de la comunidad" (Tijoux \& Palominos, 2015, p. 249). También se los asimila a extraños, es decir, aquel sujeto que surge entre categorías y estereotipos establecidos del mundo local, aquel que no encaja dentro del pulcro envase donde debería encajar. "Dicho de otro modo los extraños son los excluidos realmente de los estereotipos del orden social" (Beck, 2007, p. 51).

El inmigrante que construye su trayectoria migratoria no solo se ve sometido a racialización y exclusión en los espacios de actual residencia o por los cuales transita o permanece en Chile. Las investigaciones realizadas por María Emilia Tijoux y Gabriela Córdova (2015) complejizan discursos y prácticas racistas que no tienen una geografía exclusiva. Muchos y muchas cargan con estereotipos desde sus lugares de nacimiento, los barrios o pueblos habitados, o bien, los territorios de proximidad hacia los cuales se mueven. Muchos (as) son objetos de caricaturas, tiras cómicas, o bien son racializados por los medios de comunicación, las instituciones del Estado, los gobiernos locales y la misma sociedad aparentemente blanca.

Bajos las condiciones descritas anteriormente, se requieren más estudios que exploren sobre el sentido de un cambio, para evitar homogenizar las historias de vida de los sujetos y las sujetas inmigrantes. Este artículo tiene como principales entrevistadas (os) sujetos afrodescendientes quienes se han sometido a lo largo de su vida a geografías del terror (Rodríguez, Alfonso \& Cavelier, 2008). Parte de estas investigaciones han sido liderada por el antropólogo Eduardo Restrepo (Restrepo \& Rojas, 2004) quien ha debatido cómo los conflictos territoriales que afectan la costa Pacífica colombiana, por ejemplo, explican parte de las movilidades y migraciones complejas a las que se ven expuestas familias que nacen y viven en el Valle 
del Cauca, Antioquía y Bolívar, espacios que concentran casi el $50 \%$ de la población afrocolombiana (Rodríguez, Alfonso \& Cavelier, 2008).

La "geografía del terror" de inmigrantes (Oslender, 2004, p. 40) se materializa en restricciones implícitas o explícitas de los movimientos cotidianos (no moverse hacia ciertos lugares); la desterritorialización que puede materializarse en la falta de poder en el lugar habitado; la incapacidad de efectuar planes de manejo en sus territorios, o bien, el desplazamiento forzado que puede redundar en migraciones de corta distancia o duración o de larga distancia y duración. Gran parte de los territorios donde habitan familias afrocolombianas tienden a "ocupar un lugar subordinado en las políticas públicas y las concepciones culturales dominantes del país" (Rodríguez, Alfonso \& Cavelier, 2008, p. 25).

En este artículo se asume la complejidad de la migración definiéndola como un movimiento en ruta que se relaciona íntimamente con los territorios sobre los cuales se emprende el viaje. También considera todas las fronteras a las que se ven sometidos las personas y sus familias, y los vínculos que establecen entre los diferentes espacios que configuran su historia de vida. Asimismo, son movimientos que en muchos casos están dominado por los imaginarios que existen o se recrean respecto a determinados orígenes y sociedades.

En este contexto, debatir aquí el sentido de las trayectorias migratorias en ciudades del norte minero extractivo chileno, resulta significativo al menos por tres razones: en primer lugar, porque ellos están insertos en el imaginario de territorios mineros extractivos productores de riqueza. En segundo lugar, y relacionado a lo anterior, ese imaginario lleva a pensar a los sujetos migrantes que alcanzarán una movilidad social en ascenso con condiciones de habitabilidad mejores a las de sus lugares de origen. Finalmente, al llegar a Chile no obtienen su condición de refugio quienes sí la necesitan; no logran insertarse en la economía productiva supuestamente rica y no logran habitar en condiciones dignas como las que sí tenían en sus lugares de nacimiento (Contreras, Neville \& González, 2019).

En este artículo se propone una lectura compleja de las trayectorias migratorias, desde una perspectiva que aporte a nuevas lecturas sobre la migración y el sentido de los movimientos entre territorios y entre fronteras, que sortea la escala Estado-nación. La primera parte explora el concepto trayectoria desde la visión física métrica hasta los aportes de la producción académica referida a estudios migratorios, tanto en América Latina como en Francia.
Una segunda parte analiza los sujetos entrevistados y mapea sus trayectorias migratorias, proponiendo una tipología de trayectorias que transita entre la trayectoria directa, azarosa y nómade.

\section{Complejidad en las trayectorias migratorias}

El concepto de trayectoria se asocia a las teorías que precisan movimientos objetivos, estructurados y secuenciales. Nace desde la ingeniería y se exporta a los estudios migratorios desde diferentes estrategias: el mapeo de las rutas, la identificación y el análisis de secuencias o estadios de migración. El análisis de los datos de trayectoria es la clave para un número creciente de aplicaciones que apuntan a la comprensión y gestión global de fenómenos complejos que involucran objetos en movimiento.

Los movimientos de los sujetos migrantes no son estructurados ni responden a una racionalidad en la secuencia de viajes, entradas y salidas. Cada nodo tras movimiento es una negociación, una estrategia y un arbitraje entre múltiples factores, entre estos la familia, las condiciones de vida, la relación entre el lugar de trabajo, la residencia, la movilidad de cuidado, las condiciones de acceso y conectividad que provee un territorio, entre otros. El proyecto migratorio no responde a un marco territorio único, sino más bien comprende la multiplicidad de territorios que se conectan a través de relaciones sociales y familiares (Duvivier, 2010) en un día cotidiano.

Las investigaciones asociadas al término refieren al movimiento de un objeto desde un punto de partida a otro de destino. Algunos ejemplos clásicos están representados en el número de viajes que realiza una persona desde su casa al trabajo, número de productos distribuidos desde un lugar equis a otro territorio, es decir, viajes contables como definidores de una trayectoria (Spaccapietra et al., 2008). En consecuencia, el campo de los posibles estará mediado por recursos materiales, individuales y colectivos, pero también por las estrategias e itinerarios que despliegan los sujetos en balance con muchos criterios (Grafmeyer, 2010).

El desarrollo de investigaciones en Ciencias Sociales en los últimos veinte años resulta pertinente a la hora de ahondar sobre el concepto trayectoria. Destacan los trabajos de Susana Sassone (2007) en América Latina y en Francia son clásicos los estudios de Jean Yves Authier, Catherine Bonvalet \& Jean Pierre Levy (2010) y Émilie Duvivier (2010). Los y las autoras (es) interpelan el concepto trayectoria vinculado a estrategias de movilidad y proyectos migratorios que exigen comprender la pluralidad de los 
comportamientos de los sujetos en relación con las redes sociales, familiares, ciclos de vida y condiciones de los territorios de origen, nacimiento o residencia habitual.

Por tanto, más que referir a la geometría de los movimientos, sus rupturas $\mathrm{y} / \mathrm{o}$ permanencias, resulta atendible focalizarse en el gap de la literatura sobre migraciones y la comprensión sobre la elección o restricción territorial a la que se ven sometidas los migrantes.

Algunas investigaciones refieren no solo a la naturaleza de las migraciones o el tipo de trabajos que realizan los migrantes (Fomina \& Frelak, 2008; Vasey, 2015), sino también al sentido tras el cambio, las condiciones y opciones específicas que tiene cada sujeto migrante al momento de salir de un territorio, las motivaciones para ir al extranjero, el sentido de la movilidad social y la escala de cada movimiento y las opciones de quedarse en un determinado territorio o país (Christensen, 2017).

Las trayectorias migratorias se construyen objetivamente mediante el reconocimiento institucional y social del que son objeto los inmigrantes por parte del Estado y la sociedad, y subjetivamente a partir de la forma en que estos experimentan ese reconocimiento y lo ponderan desde sus propias expectativas. Vargas (2000) describe la trayectoria como la "sucesión de actividades de desarrollo que implican una educación formal e informal, una formación y una experiencia laboral idónea que conducen al individuo a puestos de mayor jerarquía" (p. 3). Este concepto se complementa con lo expresado por Boado (1996) sobre la forma en que la reconstrucción de las trayectorias permite recuperar el bagaje de saberes, habilidades y destrezas adquiridas por el egresado o trabajador en el desarrollo de su vida profesional.

Parte de las investigaciones se concentran en las trayectorias laborales o de estudio de los sujetos migrantes. En este sentido, la trayectoria se define como el recorrido en los distintos puestos de trabajo y actividades profesionales que desarrollan los individuos, derivadas de la formación recibida y de la combinación de factores micro y macrosociales como los antecedentes familiares, las relaciones personales, el género, el momento social del egreso, el primer empleo, las condiciones del mercado de trabajo que permiten explicar su movilidad social, económica y laboral (Jiménez, 2009).

En América Latina los trabajos de Susana Sassone (2007) y Sassone \& Lapenda (2019) resultan claves a la hora de analizar trayectorias migratorias. La autora analiza las territorialidades de los migrantes transnacionales que habitan en Buenos Aires, analiza los aspectos que vinculan territorios de frontera, así como también las dimensiones de la vida cotidiana de los migrantes que favorecen sus desplazamientos y comunicaciones. La autora le asigna un rol significativo a la familia, identidad cultural y la ciudadanía como tres dominantes a la hora de estudiar y comprender la migración. Detrás de sus investigaciones de denota al inmigrante (Tijoux \& Palominos, 2015), aunque no profundiza sobre las prácticas racistas que pesan sobre bolivianos o peruanos. Esto último exige pensar nuevas investigaciones que pongan en tensión cómo se construyen las trayectorias migratorias de sujetos y sujetas racializadas.

En conclusión, este artículo propone la trayectoria como la articulación de todos los nodos que empujan, motivan, o bien, obligan a un sujeto a emigrar de un territorio de nacimiento. Dichos nodos pueden ser nómades, transitorios, o bien, permanentes. La trayectoria alberga todas las lógicas que orientan un itinerario y los diferentes tiempos que estructuran un recorrido (Authier, Bonvalet \& Levy, 2010), pero también responden a las oportunidades del camino definido en estudios franceses como "le hasard de la route" (Duvivier, 2010, p. 245).

\section{Metodología de investigación}

El estudio de trayectorias residenciales emerge desde el análisis inicial de cincuenta entrevistas en profundidad aplicadas a inmigrantes internacionales de la región latinoamericana y del Caribe que al momento de la entrevista residen en las ciudades de Iquique, Alto Hospicio o Antofagasta. Las entrevistas fueron realizadas en diferentes momentos, entre los años 2016 y 2019. La mayoría de ellos y ellas son afrocolombianos, afrodominicanos, afrohaitianos $\mathrm{y}$ andinos (as). Menores casos peruanos y bolivianos. La secuencia de la entrevista devela un primer momento de confianza donde buscábamos conocer los motivos de su migración, las estrategias que desplegaron en cada nodo que articuló su trayectoria migratoria y las dificultades que enfrentaron en cada cruce, control fronterizo o territorio al que arribaban. Un segundo, tercero y hasta un cuarto momento se focalizó en identificar las causas y estrategias desplegadas en cada cambio de residencia realizado al interior del país de nacimiento y en los países en los que han habitado. Se buscó así conocer los contextos que explican parte de cada decisión de movilidad.

Del conjunto inicial de entrevistas realizadas fueron seleccionadas diez entrevistas en profundidad para ser trabajadas aquí, aunque tres casos son analizados con mayor profundidad en tanto son diferenciadores de las tres 
trayectorias aquí presentadas: directa, azarosa y nómada. Desde cada experiencia se identifica cómo construyen relaciones entre territorios, el sentido que adquieren las redes sociales y/o familiares, los arbitrajes a los que deben recurrir en cada nodo que articula una trayectoria y el sentido que ocupa el nodo Chile en su trayectoria migratoria. Las características de cada entrevistado se presentan en la Tabla 1 . Se resguarda la identidad de cada sujeto a través de una sigla.

Los testimonios fueron procesados mediante análisis de discurso, lo que permite la identificación de múltiples estrategias residenciales respecto a tenencia, localización o la presencia de redes sociales y familiares a lo largo de la trayectoria. Las entrevistas comprenden a ocho mujeres de entre veintisiete y cincuenta y cinco años y dos hombres entre veintiséis y cuarenta y cinco años. La mayoría tramita la visa temporal, sujeta a contrato. Menores casos pueden solicitar la permanencia definitiva, ya sea porque no tienen trabajos estables, porque necesitan ser reconocidos como refugiados políticos, o bien, por diferentes situaciones que dificultad el acceso equitativo a una visa o permanencia en Chile. Tienen trabajos informales en peluquería, limpieza de casas, trabajos en restaurantes, o bien, jefas de hogar sin trabajos estables. Solo los dos casos de entrevistados venezolanos tienen sus negocios asociados a lugares de almuerzo o pequeños restaurantes con comidas típicas de sus ciudades de origen. Pese a ello, todas y todos los aquí analizados son referentes de la economía informal, propio de economías neoliberales y desiguales como la chilena.

Del conjunto de entrevistas se mapean trayectorias migratorias de tres casos (ANG, JDY y EDO) dado que son representativas de las trayectorias presentadas como tipologías. Por tiempo no se pueden representar todas, no obstante, detrás del discurso de ellas se construye teoría. Las cartografías de trayectorias reconocen las siguientes dimensiones: recorrido emprendido desde los países -o espacios- de origen hasta el lugar de residencia actual, la diferenciación entre espacios transitorios o de asentamiento y el traspaso de fronteras político-administrativas. Mientras, complementariamente se incorporan factores del acceso a la vivienda, tales como la localización de cada residencia declarada, el tipo de vivienda declarada, entre ellas: casa, departamento, casa en campamento o pieza, su modo de tenencia, identificando: compra, arriendo o tomas de

Tabla 1

Perfil de las y los entrevistadas (os).

\begin{tabular}{|c|c|c|c|c|c|c|c|c|c|c|}
\hline $\begin{array}{l}\text { Variable Lugar de } \\
\text { Residencia actual }\end{array}$ & \multicolumn{3}{|c|}{ Iquique } & \multicolumn{3}{|c|}{ Alto Hospicio } & \multicolumn{4}{|c|}{ Antofagasta } \\
\hline $\mathrm{N}^{0}$ entrevista & Ent. 1 & Ent.2 & Ent. 3 & Ent. 4 & Ent. 5 & Ent. 6 & Ent. 7 & Ent. 8 & Ent. 9 & Ent. 10 \\
\hline $\begin{array}{l}\text { Sexo (M: Masculino; } \\
\text { F: Femenino) }\end{array}$ & M & M & $M$ & M & M & $\mathrm{H}$ & M & M & $\mathrm{H}$ & $\mathrm{H}$ \\
\hline $\begin{array}{l}\text { Edad al momento de } \\
\text { la entrevista }\end{array}$ & 53 años & 55 años & 32 años & 45 años & 42 años & 45 años & 27 años & 52 años & 29 años & 26 años \\
\hline Años en Chile & 5 años & 15 años & 9 meses & 6 años & 4 años & 10 años & 10 meses & 5 años & 6 meses & 3 años \\
\hline $\begin{array}{l}\text { Años en la ciudad de } \\
\text { actual residencia }\end{array}$ & 5 años & 15 años & 9 meses & 6 años & 4 años & 1 año & 6 meses & 5 años & 6 meses & 3 años \\
\hline País de nacimiento & $\begin{array}{l}\text { República } \\
\text { Dominicana }\end{array}$ & Colombia & Cuba & Colombia & Ecuador & Colombia & Haití & Venezuela & Haití & Venezuela \\
\hline $\begin{array}{l}\text { Composición del } \\
\text { grupo familiar }\end{array}$ & Individual & Pareja & Hijo y pareja & Hijo y pareja & Hijas e hijo & Hija y pareja & Individual & Hijo y madre & Individual & Pareja \\
\hline $\begin{array}{l}\text { Sigla asociada al } \\
\text { nombre }\end{array}$ & AUS & CON & YUN & ANG & MIN & EW & PER & JEN & JDY & EDO \\
\hline
\end{tabular}

Fuente: Elaboración propia en base a entrevistas en profundidad realizadas entre los años 2016 y 2019. VID Enlace ENL04/16 y Fondecyt Regular 1171722. 
terrenos; además de condiciones de habitabilidad como el allegamiento. La importancia de las cartografías de trayectorias yace en su papel de herramienta visual y analítica, y advierte las relaciones que se establecen entre territorios.

\section{De trayectorias migratorias directas, azarosas y nómades}

Los trabajos de Sassone (2007) y Sassone \& Lapenda (2019) resultan clave en estudios migratorios dentro de la región latinoamericana, ya que analiza desde enfoques cualitativos la forma de anclaje territorios de los migrantes, las relaciones que establecen y los vínculos entre espacios de nacimiento y lugares de actuales residencias (Sassone, 2007). Para Sassone \& Lapenda (2019), identidad y territorio son ejes claves para comprender los espacios de vida de migrantes, en este caso migrantes bolivianos y peruanos que habitan en Buenos Aires. Si bien parte de sus discusiones están focalizadas en migrantes transfronterizos, aporta en la discusión sobre los nodos que producen anclajes, o bien, que vinculan flujos de personas, información y remesas. De esa discusión se acoge la lectura territorializada en la comprensión del trayecto, aunque se cuestiona qué significa país de acogida, en tanto el sujeto inmigrante tiende a ser minimizado, racializado o excluido de algunas esferas societales.

El análisis de las trayectorias migratorias y el sentido de cada cambio de residencia, contemplado como un trade off entre múltiples razones lleva a proponer una lectura de las trayectorias que transitan entre una directa, azarosa y nómade descritas en la Tabla 2.

Se han simplificado en la Tabla 2 tipologías de trayectorias como primera aproximación, en la búsqueda de complejizar cómo los sujetos y sujetas migrantes construyen sus trayectorias y conectan nodos. Las tipologías advierten un trabajo más profundo, ya que algunos entrevistados están sometidos a dos tipos de trayectorias, dependiendo del territorio al que ingresan, transitan o permanecen. También advierten que el tiempo de residencia en un lugar no es garantía de una mayor protección ni los vuelve sujeto de derechos, en tanto la mayoría es racializado por las sociedades por las que transitan o permanecen.

La primera trayectoria se define como "directa", porque contempla el anclaje entre el lugar de nacimiento y un territorio donde habita una red familia o social que facilita su instalación, favorece los contactos para búsqueda de trabajo, o bien, apoya en el primer momento de arribo. Detrás de esta trayectoria observamos en los diez entrevistados y entrevistadas cómo ellos tienden a ser desamparados en el trayecto a pesar de tener redes y relaciones tejidas antes de salir del lugar de origen o de última residencia antes de ingresar al país.

La trayectoria directa caracteriza a sujetos inmigrantes que llevan aproximadamente seis meses en Chile hasta

Tabla 2

Tipologías migrantes. Directa, azarosa y nómade.

\begin{tabular}{|c|c|c|c|c|}
\hline Tipo Trayectoria & Características & $\begin{array}{l}\text { Factores principales } \\
\text { tras la emigración }\end{array}$ & $\begin{array}{l}\text { Tiempo de } \\
\text { permanencia en } \\
\text { Chile }\end{array}$ & $\begin{array}{l}N^{\circ} \text { cambios de } \\
\text { residencia antes de } \\
\text { llegar a Chile (años) }\end{array}$ \\
\hline Directa & $\begin{array}{l}\text { Trayectorias que tienden a conectar lugar } \\
\text { de origen y de actual residencia de una red } \\
\text { social y/o familiar. }\end{array}$ & $\begin{array}{l}\text { Mejora condiciones de } \\
\text { habitabilidad y de vida. } \\
\text { Mejores oportunidades } \\
\text { laborales. Reunificación } \\
\text { familiar. }\end{array}$ & 6 meses a 7 años & 1 a 2 \\
\hline Azarosa & $\begin{array}{l}\text { Construcción de trayectorias que relacionan } \\
\text { una multiplicidad de territorios según la } \\
\text { capacidad de negociación, arbitrajes, } \\
\text { restricciones a las que se ven sometidos los } \\
\text { inmigrantes. }\end{array}$ & $\begin{array}{l}\text { Desplazamientos forzados } \\
\text { o involuntarios. Racismo, } \\
\text { violencia y maltrato. }\end{array}$ & 5 a 15 años & 1 a 4 \\
\hline Nómade & $\begin{array}{l}\text { Trayectorias migratorias basadas en } \\
\text { multiplicidad de territorios donde existen } \\
\text { redes sociales y/o familiares preexistentes. } \\
\text { Representa la trayectoria de familias con } \\
\text { historia migratoria. Alberga a los grupos con } \\
\text { mayores recursos de movilidad. }\end{array}$ & $\begin{array}{l}\text { Mejores oportunidades } \\
\text { laborales fundados en la } \\
\text { existencia de redes. }\end{array}$ & 9 meses a 3 años & 1 a 2 \\
\hline
\end{tabular}

Fuente: Autora a partir del análisis de entrevistas en profundidad realizadas entre los años 2016, 2017, 2018 y 2019 . VID Enlace ENL04/16 y Fondecyt Regular 1171722. 
aquellos que habitan casi siete años en ciudades del norte. Comprende a hijos de familias afrohaitianas, afrodominicanas y afrocolombianas. Considera, por lo tanto, a sujetos inmigrantes que inician su trayectoria migratoria o aquellos que se han consolidado en el país a pesar de no tener permanencia definitiva, ni trabajo formal. La mayoría de los entrevistados que construyeron una trayectoria bipolar tuvo menos de dos cambios de residencia en su lugar de nacimiento.

En segundo lugar, la Tabla 2 reconoce trayectorias azarosas representadas por aquellos sujetos (as) inmigrantes que salen de sus territorios de origen por conflictos asociados a desplazamientos forzados o involuntarios, racismo, violencia y maltrato. Son los y las sujetas más violentadas del grupo aquí estudiado, condición que explica cómo van articulando una red de nodos territoriales que emergen en ruta y que responden al nivel de agenciamiento que ellos y ellas logran en la medida que realizan viajes que no tienen necesariamente un territorio de destino. Son víctimas de conflictos y racismos, lo que reconoce que en Chile no se ha considerado su condición de refugiados políticos, sintiéndose racializados por las prácticas, discursos y estereotipos que pesan sobre ellos. Este grupo, además, comprende a sujetos que tienen como aspiración en el norte de Chile ser propietarios de una vivienda, idealmente autoconstruida, pues ven hasta el momento de la entrevista la imposibilidad de regreso al lugar de nacimiento. Son los encarcelados por políticas de extranjería dentro de la región latinoamericana, Andina y del Caribe.

El tercer grupo comprende las trayectorias nómades representadas por aquellas y aquellos sujetos inmigrantes para los cuales Chile podía ser o no un lugar donde habitar o transitar. Comprende a sujetos y sujetas inmigrantes que tienen una historia familiar migratoria, que están dispuestos a viajar a sitios por los cuales ya han circulado, o bien, permanecido. Los nodos que explican sus movimientos también se sustentan en la existencia de redes sociales y/o familiares. Son negociadores en cada territorio donde habitan, en tanto desde sus trayectorias aspiran a una movilidad social en ascenso.

Tanto los y las sujetos (as) inmigrantes que tienen trayectorias directas o azarosas se vuelven comunes en términos de las condiciones materiales en las que han vivido, la mayoría precaria, a pesar de que reconocen que la trayectoria migratoria los sitúa en una movilidad social que sienten en descenso. Todos los entrevistados representan a la sociedad de la inseguridad total (Castel, 2013). Se sienten liberados de toda regulación colectiva, viviendo bajo el signo de la amenaza permanente porque no poseen en sí mismos el poder de proteger y protegerse. Todos (as) son comunes en la medida que han movilizado sus propios recursos para moverse. A su vez, declaran sentirse en un estado permanente de incertidumbre e inseguridad no pudiendo "dominar el presente ni anticipar posiblemente el porvenir" (Castel, 2013, p. 40).

\section{Trayectorias directas}

Las trayectorias directas representan a sujetos (as) inmigrantes que provienen mayoritariamente de Haití, República Dominicana y Colombia. Parte de ellos o ellas han tenido cambios de residencia al interior de sus países o desde Haití a República Dominicana. En este último caso, la mayoría de los y las entrevistadas viaja a República Dominica con el propósito de lograr una movilidad socioprofesional ascendente, estudiar alguna carrera o mejorar sus condiciones de vida. Indistintamente la nacionalidad, la mayoría de los entrevistados tenía conocidos, amigos o algún familiar que apoyaba la necesidad de salir del lugar de nacimiento. Para ellos, Chile es reflejo de un imaginario basado en lugar de mejores oportunidades económicas y laborales, condición ilusoria que descubren en la medida que ingresan al país e intentan negociar un lugar donde habitar.

Del conjunto de entrevistas (Tabla 1), se escogió la historia de JDY cuya trayectoria se resumen en la Figura 1. Él es profesor de inglés haitiano, residente en la ciudad de Antofagasta. Tiene veintinueve años, vive hace seis meses en la ciudad de Antofagasta. Se movió desde Cabo Haitiano hacia Puerto Príncipe y vivía en una casa de dos pisos con sus padres. Hijo de padres que tenían ocho hermanos. Reconoce que todos vivían juntos en la misma cama. Pasó por República Dominicana durante seis años a estudiar. Llegó a Chile siguiendo a un amigo que se vino a trabajar.

Siempre hay personas que dicen que sí hay oportunidades. Eso es un eslogan, a nosotros siempre el país de nosotros no nos da oportunidad. Siempre buscamos otra puerta a ver si podemos salir. Yo personalmente no he querido venir a Chile. Yo estudié informática y yo digo sí, por suerte sí. En la República Dominicana tampoco hay oportunidad porque no tenía la cédula dominicana o residencia. A los haitianos no nos dan residencia, por eso no había oportunidad en mi país, tampoco donde estudiaba, por eso he decidido venir acá a Chile (JDY, entrevista en profundidad, Antofagasta, 2018). 


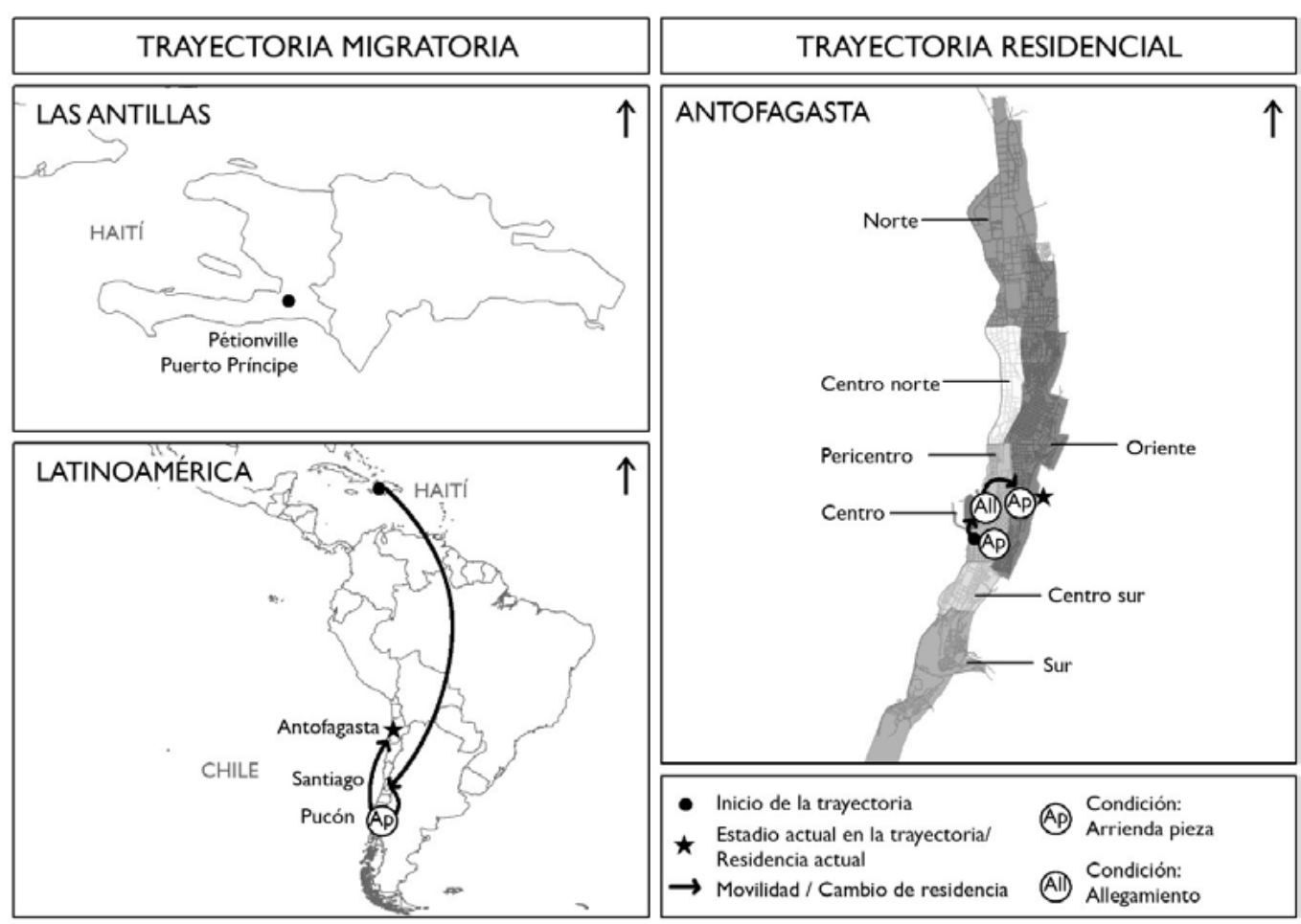

Figura 1. Caso de JDY, profesor de inglés haitiano, veintinueve años, reside en Chile hace seis meses en la ciudad de Antofagasta. Fuente: Fondecyt 1171722. Figura construida por Beatriz Seguel.

La historia de JDY tensiona dos cosas: las restricciones y asimetrías que imponen países transfronterizos como República Dominicana respecto a Haití y, en segundo lugar, cuestiona hasta qué punto Chile es un territorio de atracción migratoria.

A veces uno va a un lugar porque uno puede hallar... estoy adivinando, uno va a una ciudad porque a veces la cosa o puede encontrar una pega, pero uno no tiene la ciudad exacta, mañana si me dicen tengo que ir a Santiago a trabajar me voy, si tengo un amigo que me dice venga a Calama, voy (JDY, entrevista en profundidad, Antofagasta,2017).

La mayoría de los y las entrevistadas se encuentran en condición de irregularidad, ya sea porque no han conseguido un trabajo formal, establecido y bien remunerado, o también porque por diferentes causas, algunas arbitrarias, no han recibido su permanencia definitiva o su visa sujeta a contrato. Parte de los entrevistados, indistintamente su tipo de trayectoria, representan a sujetos precarizados y violentados aún más por una política de extranjería que les niega su condición de sujetos de derechos.
Es muy difícil acceder a la universidad en Haití, pero era más fácil acceder a la universidad de República Dominicana. Por eso nos fuimos allá a estudiar, no solamente yo, la mayoría de las personas que vienen de la clase media mandan a sus hijos a estudiar allá, la persona de clase alta la nada para EE.UU., Francia, Chile, esos países (JDY, entrevista en profundidad, Antofagasta, 2018).

A su vez, la trayectoria de JDY también evidencia el racismo a la que la mayoría de sujetos haitianos se han visto sometidos, en tanto la presencia de un país próximo como República Dominicana, representada en un Estado que ha fomentado una consciencia racista entre los dominicanos al destacarse solamente los aspectos negativos de la invasión haitiana sin proyecta o valorar la invasión como un hecho histórico (Ruiz, 2006). Parte del racismo también explica por qué al interior de la ciudad de Antofagasta hay tres cambios de residencia: habitan primero en el centro de la ciudad en condición de allegamiento, para pasar posteriormente a arrendar piezas al interior de casas en condiciones de habitabilidad precarias. 
Cada nodo que comprende los recorridos migratorios de sujetos como DY y otros entrevistados evidencia el rol de las redes sociales y/o familiares en asegurar el arribo al país. Sin embargo, ellos cuestionan de qué forma las redes pueden favorecer a habitar en mejores condiciones respecto a las que ellos concebían antes de emprender el viaje.

\section{Trayectorias azarosas}

Comprende a sujetos "atrapados en una red de otros procesos" como sostuviera Saskia Sassen (2003) al referir a todos los procesos, controles y actores a los que se ven sometidos quienes se mueven de un país a otro. Parte de los aquí entrevistados se ven enfrentados a las asimetrías entre países transfronterizos, control y arbitrariedad estatal sobre la inmigración, la persistencia de políticas de extranjería y de migración entre un país y otro; la transgresión de acuerdos internacionales sobre derechos humanos, la extinción de derechos sociales y políticos a los inmigrantes, o bien, la "multiplicación de actores políticos involucrados en la cuestión de la inmigración y los efectos interactivos entre la inmigración y otros proceso" (Sassen, 2003, p. 46). Lo anterior, no evade que este rasgo de la construcción trayectoria también es parte de las arbitrariedades a las que se ven sometidos los afrodescendientes que construyen trayectorias directas, aparentemente facilitadoras.

Parte de las y los entrevistados vienen del sur colombiano afectados por desplazamientos internos vinculados al conflicto armado. Los desplazamientos tienden a estar asociados a "amenazas contra la vida y desastres naturales" (Rodríguez, Alfonso \& Cavelier, 2008, p. 28). Declaran habitar en condiciones precarias, especialmente aquellos que vivían en territorios rurales de Buenaventura. Parte del desplazamiento al que se ven sometidos los entrevistados se enmarca en la marginalización y vulnerabilidad de los espacios por ellos habitados, vinculado, además, al rol de la minería y la producción agrícola que en sus territorios impone severas presiones sobre territorios ancestrales. A su vez, la debilidad en la protección jurídica es otra de las causas que empuja sus desplazamientos voluntarios o forzados (ACNUR, 2012). Algunos datos develan que el conflicto ha desplazado a más de 8,1 millones de colombianos desde 1985. Más de 48.000 personas fueron desplazadas entre enero y septiembre de 2018 (HRW, 2018).

La Figura 2 resume la trayectoria migratoria y los cambios de residencia de ANG, mujer afrocolombiana, enfermera, nacida en Cali, específicamente en el barrio Jorge Eliecer Gaitán en el centro de ciudad de Cali, Colombia. Tiene cuarenta y cinco años, una pareja y un hijo. A los catorce años se movió al barrio Petecuy o Petebala dentro del mismo Cali. Intenta ahorrar para validar su título, o bien, estudiar enfermería o técnico en enfermería. En su relato hace explícito la falta de reconocimiento de los títulos acá en Chile. Actualmente lidera diferentes proyectos comunitarios y tiene múltiples trabajos informales.

Parte de sus cambios al interior de Colombia están dominados por el rol de jefe de hogar que tuvo que asumir su madre cuando su esposo la dejó para irse a buscar mejores condiciones laborales en Venezuela. Su padre los abandonó y no envió remesas, obligando a ANG y sus hermanos a desplegar diferentes estrategias de subsistencia en territorios complejos, dominados por el desplazamiento y la violencia.

El relato de ANG explicita las condiciones de hacinamiento que formaron parte de su trayectoria residencial y migratoria:

Mi mamá se compró un terreno... bueno la verdad no es esa, la verdad es que llega el M-19 a Cali... cuando se formó el M-19 en los años 80... Pizarro y toda la cosa... y ellos se toman el terreno, la hacienda donde sembrábamos... se tomaron ese terreno y tuvimos que cambiarnos de un lado para otro. Petecuy se dividió en tres etapas, la pelea de quien era el cacique... empezamos a enfrentarnos... mataban y de todo... entonces le colocaron "Petebala" (ANG, entrevista en profundidad, Iquique, 2016).

Uno igual ve también a los amigos morirse, porque cuando se van al M-19 y empezamos las pandillas la gente se mataba... peleando, defendiendo territorio. Allá hay líneas imaginarias. No podíamos pasar... los que vivíamos en la primera a la segunda (ANG, entrevista en profundidad, Alto Hospicio, 2017).

La violencia extrema a la que se vio sometida ANG y otros entrevistados afectados por los desplazamientos forzados, explica en parte la construcción azarosa de sus trayectorias migratorias y residenciales. Los relatos de violencias son descritos por todos los afrocolombianos aquí entrevistados. La diferencia en el caso de las mujeres es la violencia de género a la que todas ellas se exponen durante toda su vida.

Según Amnistía Internacional (2008), la violencia del conflicto armado colombiano ha afectado principalmente a una población civil que bajo ninguna circunstancia podría prevenir tal escala de agresiones. Con ello, las mujeres se han visto considerablemente perjudicadas, 


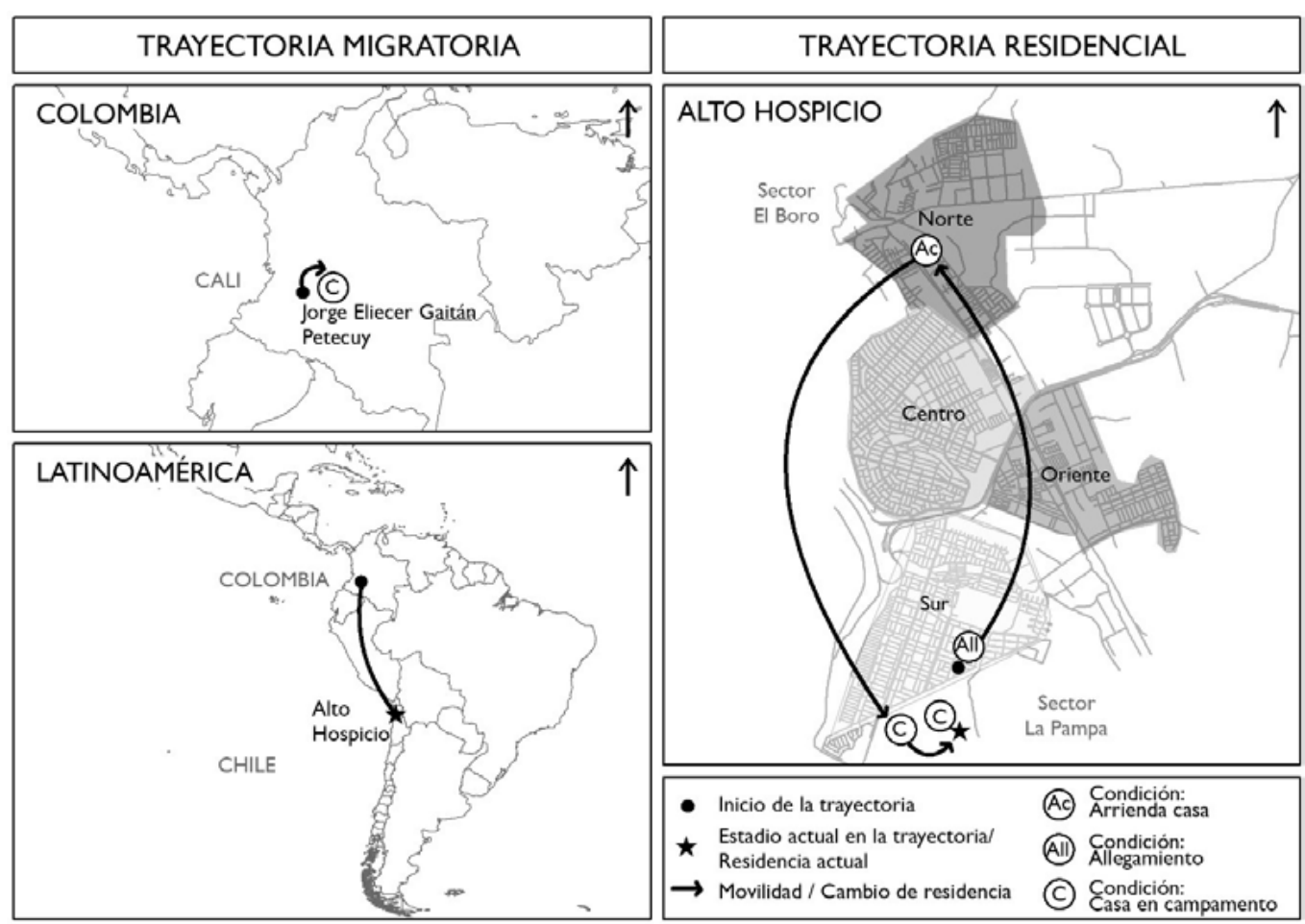

Figura 2. Caso ANG, mujer, cuarenta y cinco años, en pareja, un hijo. Reside hace seis años en Alto Hospicio. Fuente: Fondecyt 1171722. Figura construida por Beatriz Seguel.

ya que la posibilidad de ser asesinadas, secuestradas, torturadas o agredidas sexualmente no implica un daño colateral, en tanto se les ha atacado de forma deliberada debido a su identidad, actividad o lugar de residencia (Amnistía Internacional , 2008) cuya incertidumbre las puede alcanzar en la calle, sus lugares de trabajo e incluso en su propio hogar.

En el caso de ANG, la violencia sexual también explica los efectos de la condición de hacinamiento a la que se vio expuesta en gran parte de su vida. Lo anterior, explica por qué Chile y, en específico, Alto Hospicio son espacios donde el acceso al suelo y la propiedad de la vivienda se configuran en proyectos residenciales que producen mayor sensación de bienestar respecto a los recuerdos que ella guarda de la trayectoria residencial al interior de su ciudad de origen. Esta condición de habitar en campamentos es transversal a todas y todos los aquí entrevistados. Los campamentos se convierten en espacios que aseguran tranquilidad y que amparan parte de sus proyecciones residenciales, al menos al momento de la entrevista.

Sí, porque cuando nosotros con el M-19 dio los terrenos $\mathrm{y}$ todo, nosotros encerramos el terreno, pero no nos fuimos a vivir de una, porque como igual vivíamos en la casa de mi abuela, sino que mi mamá la fue construyendo poco a poco, y cuando la terminó de construir nos fuimos (ANG, entrevista en profundidad, Alto Hospicio, 2018).

La construcción azarosa de la trayectoria migratoria se inscribe en decisiones, arbitrajes y limitaciones con las que los y las entrevistados (as) se encuentran al momento de salir de sus espacios de nacimiento, enfrentarse a territorios próximos donde habitan clases sociales aparentemente blancas y con supuestas condiciones de vida superiores. La consolidación del racismo a la que se ven sometidos los entrevistados marca toda la trayectoria de vida y las estrategias que deben desplegar para cruzar una frontera, negociar sus cruces, acceder al suelo, a la vivienda, por nombrar algunas violencias que dominan su vida. En este escenario, Chile aparece como territorio que responde a un imaginario de espacio productivo, solidario y acogedor.

ANG conoció sobre Chile en ruta. Llegó a Alto Hospicio a partir de una mujer que conoció en un bus. Llego a Chile desde Tacna y fue construyendo un imaginario en torno a los relatos de otros pasajeros, quienes también tenían 
como expectativas insertarse en un mercado laboral aparentemente productivo y bien remunerado.

Chile fue porque se dieron las cosas, no conocía Chile, ni sabía dónde quedaba Chile... nomás escuchaba cuando jugaban la Copa Libertadores o la minera, pero yo geográficamente no sé dónde quedaba Chile... buscaba México, busqué Centro América... Costa Rica... pero la opción que tenía fue México... un muchacho me dijo, yo le pregunté... porque en ese tiempo había mucho lo que era... la gente empezaba a traficar con los pasaportes (ANG, entrevista en profundidad, Alto Hospicio, 2018).

Bueno, hasta que nos cogimos un colectivo que nos... desde Tacna, nadie nos quería traer... y cogimos un colectivo, porque no teníamos papeles... un señor nos paró, nos trajo... "yo los llevo, pero vean... usted se presenta solo, porque ella es negra ( $\mathrm{mi}$ esposo es blanco)... porque ellos son negros (mi hijo y yo) y son colombianos... entonces usted pasa como chileno porque usted es blanco, y a ellos no los dejan pasar". No nos dejaban pasar por el color de la piel (ANG, entrevista en profundidad, Alto Hospicio, 2019).

Los relatos anteriores advierten cómo el racismo es un factor que explica lo azaroso de una trayectoria migratoria y de un cambio de residencia, en el caso de afrodescendientes entrevistados (as). El racismo se evidencia en "actos de las intenciones o de la conciencia de algunos actores" (Fanon, 1973, p. 37) donde tanto la sociedad chilena, colombiana y dominicana mantienen a sujetos afrodescendientes en una situación de inferioridad, porque aplican mecanismos no percibidos, además de otros bastante explícitos, ya sea al momento de cruzar la frontera, solicitar refugio, el desarrollo de prácticas abusivas en los controles migratorios, pago por realizar determinados cruces, tratas y maltrato físico y verbal, entre otros. Todos estos abusos los vivió tanto al interior de su país, como en los territorios por los cuales cruzó (diferentes barrios de Lima, Tacna y en la frontera Tacna-Arica).

Sí, una compañera de trabajo... bueno, la gente empieza a migrar a Chile como en los años $90 \ldots$ la gente de Colombia empieza a migrar acá como en el 2010 yo creo... la migración colombiana para Chile... se empieza a hablar de Chile, la minera... mi amiga viaja y yo tengo contacto con ella y me dice que sí, que Chile... me dijo "véngase", y yo me vine... pero cuando llegamos acá no la volví a ver... cuando llegamos a Lima la llamé y ya no estaba (ANG, entrevista en profundidad, Alto Hospicio, 2016).
El ingreso de ANG y su familia resultó complejo. La mujer que conoció en ruta tenía un hijo viviendo en Alto Hospicio, Chile. Él sería el nexo para ingresar al país y facilitar la instalación. Sin embargo, al cruzar la frontera chilena fue abandonada por la mujer y el hijo no contestaba las llamadas. En este escenario aparece como alternativa residencial Alto Hospicio, lugar desconocido para ANG y su familia. El 31 de diciembre se convirtió en una fecha significativa para ella. Ingresó a Chile en colectivo. Le cuesta explicar por qué la policía no exigió papeles ni dinero, como sí lo hacía con otras personas que ella fue conociendo en el tiempo. También agradece la compañía del chofer, quien los dejó en Arica y entregó indicaciones de cómo llegar a Alto Hospicio.

ANG llega a Hospicio y al ingreso del país recordó a una compañera de trabajo colombiana que vivía supuestamente en Iquique. La llamó y le pidió apoyo. Su amiga vivía en Alto Hospicio y la ayudó contactándola con un hombre que necesitaba que le cuidaran un terreno. Ahí vivió tres meses al interior de una bodega que tenía dos habitaciones, cocina y baño. Trabajó informalmente en la venta de comida, hasta que con el tiempo ella y su pareja consiguieron trabajos informales, pero más estables. Posteriormente, fortaleció redes sociales que se configuraron como actores clave para sus cambios de casa. Ella ha vivido en diferentes sectores de Alto Hospicio. Cada nodo representado en la Figura 2 devela negociaciones y desalojos. Arrendó un pequeño departamento, vivió de allegada en casa de redes que fue generando, tal como se referencia en la Figura 2. En la actualidad tiene su casa en un campamento en el sector La Pampa y se encuentra liderando un proceso de radicación, dominado por desalojos abusivos, maltrato y racismo.

El caso de la mujer afrocolombiana anteriormente analizada y los afrohaitianos y dominicanos presentados en la Tabla 1 , emprenden trayectorias azarozas dominadas por la violencia, como factor desencadenante de una trayectoria discontinua. Lo anterior resulta complejo en el caso de las mujeres aquí analizadas. En su condición de mujeres afro tienden a verse sometidas a violencias en toda la trayectoria migratoria. Situación diferente es del caso de los hombres, quienes identifican la violencia en el lugar de nacimiento o de vida antes de llegar a Chile.

Los relatos precedentes nos aproximan a una discusión que no es propia de este artículo, pero que debe considerarse al momento de analizarse una trayectoria. El contexto de violencia de género que existe en la región latinoamericana, Andina y del Caribe y la importancia del territorio en las trayectorias de agresiones exigen complejizar algunas 

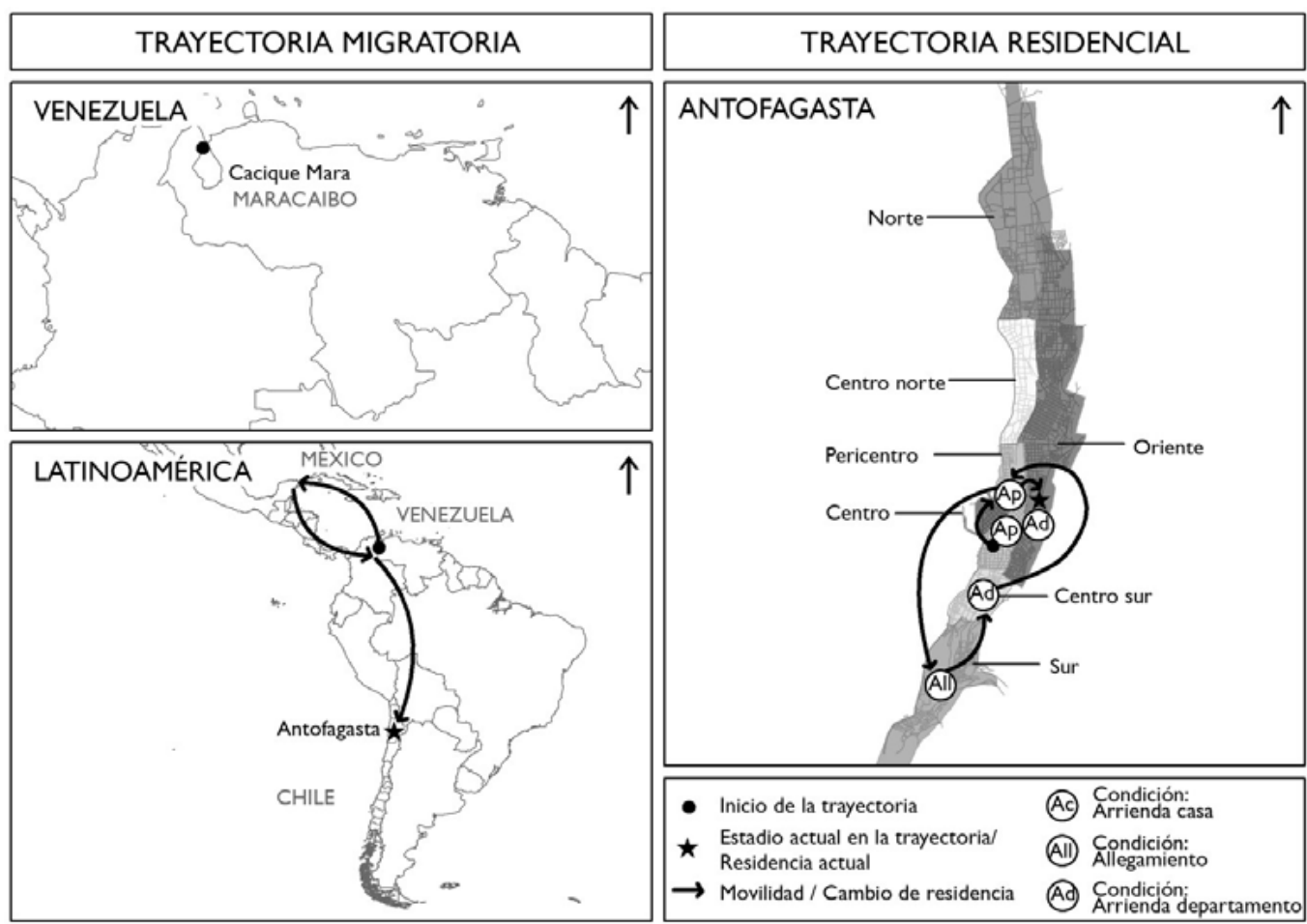

Figura 3. Caso EDO, hombre, veintiséis años, residente de la ciudad intermedia de Antofagasta, venezolano. Fuente: Fondecyt 1171722. Figura construida por Beatriz Seguel.

trayectorias. Algunas nacen en espacios donde soportan violencias cargadas de una historicidad, las cuales no tienen una geografía específica, pues son observables en ámbitos urbanos y rurales, que pueden ocurrir dentro y fuera de sus comunidades (Segato, 2016). Al migrar se identifican similitudes en las vivencias y una continuidad territorial de las violencias, en tanto se agudiza la probabilidad de sufrir agresiones físicas, sicológicas, sexuales y racistas. La mayoría se ve sometida a la criminalización de las violencias en las fronteras Estado-nación.

\section{Trayectorias nómades}

Están representadas por sujetos (as) inmigrantes invisibilizados y representativos de la dualidad y contradicción de los Estados naciones entre sujetos inmigrantes que son parte de la circulación de trabajadores de servicios, personas de negocios, o bien, trabajadores temporarios que enriquecen las economías de determinados países. Por otro lado, algunos de ellos (as) están sometidos a privatización de derechos que mejoren sus condiciones de vida, en tanto tienden a someterse a las regulaciones que imponen algunos países, o bien, sus instituciones que tienden a ser contradictorias en la forma de abordar los derechos humanos y su relación con políticas migratorias. Tal como sostiene Sassen "la política oficial de inmigración no es hoy en día parte de las nuevas reglas de juego" (2003, p. 62).

El caso de EDO (Tabla 1), hombre de veintiséis años, es representativo de la migración venezolana que ha llegado a Chile en los últimos años, aunque con mayor intensidad en los tres últimos años. Según registros del Censo de Población y Vivienda (Instituto Nacional de Estadísticas [INE], 2019 ), los venezolanos comprenden aproximadamente 290 mil residentes en el país, lo que equivale a casi el $24 \%$ de la población migrante que vive en Chile. Más de 1 millón 500 mil venezolanos han salido del país por diferentes motivaciones: inseguridad en diferentes dimensiones, como miedo a ser secuestrado, desempleo, la búsqueda de mejores expectativas de vida, pero también el rechazo del proyecto político bolivariano (Mateo \& Ledezma, 2006; Salgado, Contreras \& Albornoz, 2017).

EDO nació en ciudad de Maracaibo, específicamente en el barrio Parroquia Cacique Mara. Su papá fue pionero en el lugar, accediendo a un terreno baldío sobre el cual construyó con el tiempo una vivienda. Sus padres invirtieron 
parte de sus recursos en la educación de EDO. Él vivió en Maracaibo con sus padres y se mudó un tiempo a Cancún, México, por aproximadamente un año. El cambio se asoció a la búsqueda de mejores condiciones de vida, para aprovechar redes sociales y familiares que hace más de diez años habían partido a México. Pese a la acogida que tuvo en Cancún, decidió regresar a Venezuela para apoyar económicamente a sus padres. A su arribo, invirtió sus ahorros en una tienda de ropa.

Diez amigos nos fuimos inicialmente de vacaciones a Cancún, porque teníamos otros amigos y familiares allá. Como la cosa estaba media especial en Venezuela, siempre le dije a mi primo que si allá encontraba trabajo me quedaba. Pero después regresé para apoyar a mis papás. Coloqué una tienda de ropa. Antes de irme ya tenía esta tienda en realidad, pero la trabajaban otras personas, porque yo me dedicaba a mandar ropa para otros lugares como Aruba (EDO, entrevista en profundidad, Antofagasta, 2018).

Parte de la trayectoria migratoria de EDO se explica por las condiciones materiales y la movilidad social que caracterizaba su historia de vida. Tener recursos y ahorro facilitó su movilidad por México e incluso por República Dominicana, aunque este último país no fue mapeado en la Figura 3, ya que el entrevistado no lo consideró como destino, sino más bien como un lugar de tránsito dominado por redes existentes y por las condiciones laborales inciertas en Venezuela.

Al igual que la trayectoria directa, sus cambios están dominados por la existencia de redes sociales $\mathrm{y} / \mathrm{o}$ familiares. Sin embargo, situaciones que ocurren en su vida explican las decisiones de sus cambios y también la discontinuidad de sus movimientos. Luego de sufrir un robo con violencia en el año 2016 en Venezuela se propuso viajar a Argentina, ya que sus primos y parte de su familia se había movilizado hacia ese país.

Tengo un primo argentino. Era el 2015, él viajó en enero a Argentina. Viajó y yo hablaba con él, cuando a mí me robaron, yo dije que me iba. Empecé a hablar con mi primo y me dijo lo que necesitaba. En ese momento había muchos problemas con el tema de pasajes aéreos. Me dice mi primo vivamos juntos. Me fui a Argentina, no a Chile. Me fui por tierra con otro primo rumbo a Argentina. Cruzando la trocha o selva, al cruzar la frontera de Venezuela con Colombia nos agarraron unos guardias venezolanos, nos quitaron algunas cosas para poder dejarnos pasar y nos tocó pasar el río con la maleta (EDO, entrevista en profundidad, Antofagasta, 2018).

El relato de EDO advierte el cruce entre trayectorias azarosas y nómades. Lo diferente radica en que los entrevistados aquí tienen historias migratorias con familiares que viven hace más de veinte años en España, Estados Unidos, México y Argentina. La presencia de diferentes nodos en distintos países favorece que ellos tiendan a ser sujetos multimóviles. Sin embargo, los dos casos que se presentan como transfronterizos nómades no han quedado exentos de violencias en ruta, aunque la diferencia con el caso de ANG (trayectoria azarosa) no se ven afectados a discursos y prácticas racistas. Más bien, ellos son objeto de redes de trata y tráfico de migrantes en las zonas fronterizas de Latinoamérica.

En Ipiales cruzamos allí a Ecuador. En Ecuador nos quitaron plata los guardias fronterizos para el desayuno pero también nos sellaron normal y de ahí cogimos a Lima, un bus a Lima, perdón a Quito, y luego de Quito tomamos otro que iba a Tumbes, que Tumbes es la frontera de Ecuador con Perú, súper peligrosa, nosotros íbamos al terminal y no lo abrían hasta las ocho y eran como las seis, y la gente nos decía agarren allí las maletas porque se las quitan y salen corriendo, bueno luego cruzamos a Lima que ahí si no recuerdo... Tumbes, Guaquilla creo que es, de esa forma ingresamos a Perú, de Perú llegamos a Lima, de Lima a Tacna (EDO, entrevista en profundidad, Antofagasta, 2018).

Pese a las redes migratorias de EDO, la trayectoria hacia Argentina adquirió rasgos similares a una trayectoria azarosa. Su relato en momentos es contradictorio, pero es parte de una estrategia de sobrevivencia que ha debido desplegar en todos los sitios habitados. Insistió que Argentina era el territorio donde quería iniciar un nuevo proyecto de vida. Sin embargo, cuando se adquiere confianza con EDO describe que Chile apareció como un nodo a medida que en ruta se dio cuenta de lo difícil que era la situación económica en Argentina, y de las dificultades que significa cruzar fronteras por tierra en América Latina. Asimismo, sostiene en su relato que las redes sociales en los diferentes destinos no operaron cuando decide viajar a Argentina. La situación económica y política de la región resultaba compleja, y los ahorros habían mermado a medida que fue ayudando a sus padres. También evidencia cómo ser clase media en Venezuela no asegura una trayectoria de vida en ascenso. Si bien parte de sus veinte años se inscribió en una movilidad social 
en ascenso, esto resultó insuficiente frente a la crisis que tuvo que enfrentar en su país.

En consecuencia, los dos casos analizados como trayectorias nómades tienen como rasgo común sentirse cautivos , a veces capaces de moverse, favorecidos por sus redes sociales o familiares, pero en otros momentos sienten que cualquier viaje es incierto. La diferencia de este tipo de trayectoria es que, dentro de las estrategias de movilidad, la sedentarización no es parte del tipo de vida al que desean inscribirse.

La pluralidad de comportamientos que desarrollan los migrantes con trayectorias nómades invita incluso a superar oposiciones entre lo nómada, constantemente móvil y permanente (Duvivier, 2010). Si bien se han separado los casos, existen rasgos de cada trayectoria que se superponen. Los entrevistados son parte de la inseguridad social en la que se inscriben clases medias latinoamericanas en un contexto globalizante y desigual (Figura 3).

Al igual que todos y todas las entrevistadas, EDO habitó en una pieza en el centro de Antofagasta, vivió de allegado en casa de amigos que armó al ingresar a Chile, en la parte sur de Antofagasta. Sin embargo, el rasgo diferenciador de EDO respecto al resto de entrevistados está dominado por la necesidad de evidenciar que a pesar de las vicisitudes que experimentó en su trayectoria migratoria tiene ahorros que le permiten habitar en un departamento alquilado en el centro de Antofagasta, próximo a Avenida Brasil. Habitar en un departamento, alquilado con amigos es, además, un elemento de diferencia que él denota respecto a otros inmigrantes:

Tuve la suerte que la señora que me arrienda si bien me exigió papeles, no cuestionó que no tuviera liquidaciones para mostrarle. Porque aún no liquido, recién monté el negocio de comida y este pequeño restaurante. Además, estoy trayendo a mis papás y no podemos vivir en cualquier parte. Acá tengo el negocio, todo cerca. No me gustaría vivir en los campamentos. Veo mucha pobreza (EDO, entrevista en profundidad, Antofagasta, 2018).

Tanto los entrevistados (as) que representan trayectorias directas, nómadas y azarosas (Tabla 2 y Figuras 1, 2 y 3 ) habitan en ciudades minero extractivas duales. Por un lado, ninguno (a) de los entrevistados trabaja en minería ni en actividades vinculadas a dicha actividad. Resulta cuestionable como una ciudad minero extractiva como Antofagasta inserta en una compleja red transnacional, genere riqueza y no la distribuyan de forma equitativa en los territorios de sacrificio donde se producen, explotan y exportan recursos naturales (Arboleda, 2018). Los y las entrevistadas están insertos en una economía global, orientada a proporcionar alimentos a las familias que provienen de sus países de nacimiento. Esta economía de enclave es la que ha favorecido el conocimiento entre ellos, asegurando subsistencia. En segundo lugar, los más desfavorecidos y racializados ven el mercado de suelo y de acceso a la vivienda restrictivo, en tanto las ofertas están pensadas para sujetos mejor pagadores del suelo, trabajadores de la minería y no necesariamente para la población que demanda vivienda en Antofagasta. Lo anterior redunda en aumento en la desigualdad de ingresos que se ha dado como consecuencia de procesos recientes de concentración y capitalización en las industrias minera y portuaria también han exacerbado la fragmentación socioespacial en Antofagasta (Arboleda, 2018).

\section{Conclusiones}

La construcción de tipos de trayectorias se configura como un ejercicio inicial de exploración que más que buscar ser replicado, invita a complejizar el sentido detrás de un movimiento, indistintamente la naturaleza de estos. Desde las trayectorias aquí analizadas, se advierte también la complejidad de ellas, las violencias y racismos a las que se ven sometidas al interior de sus territorios o al cambiar de residencia al interior de Chile.

Uno de los hallazgos del análisis de las trayectorias migratorias es la propuesta de trayectorias que rompe con la tesis de supuesta sociedad chilena de acogida. Ninguno de los y las entrevistadas siente que este territorio sea solidario, equitativo y favorezca sus expectativas de vida. Chile más que ser un destino deseado, evidencia la destrucción de los imaginarios sobre territorios neoliberales reproductores de desigualdad e inequidad. Todas y todos coinciden que sus condiciones de habitabilidad y de inserción laboral son inferiores a las vividas en los espacios transitados y de permanencia. Algunos (as) se sienten encarcelados en una red de migraciones ancladas en políticas racistas y clasistas ¿Un país con una sociedad racista y especuladora podría adscribir a lo que algunos autores plantean como sociedad de acogida?

Desde una primera construcción de tres tipologías de trayectorias (directas, azarosas y nómades) se concluye que una trayectoria migratoria comprende la articulación de todos los nodos que explican la salida de un lugar, el tránsito por otro y la permanencia. Una trayectoria rompe con la tradicional idea de que los sujetos migrantes salen de 
un lugar de destino y llegan a otro de supuesta acogida. La condición de acogida es puesta en tensión en dos sentidos: muchas de las trayectorias no coinciden con los proyectos originales de los sujetos, más bien habitan actualmente en territorios que fueron parte de negociaciones en ruta $\mathrm{y}$, en segundo lugar, algunas y algunas son sometidos a discursos y prácticas racistas.

En este sentido, el concepto de trayectoria estimula los estudios migratorios dado que permite identificar cuáles son las estrategias, restricciones y posibilitantes que encuentra un sujeto migrante al momento de transar y decidir un cambio. Si bien existe consenso en la literatura que cada cambio es un trade off entre múltiples factores, la trayectoria migratoria permite ahondar sobre las múltiples relaciones entre territorios, cuestiona efectivamente el rol de redes sociales en la construcción de la trayectoria y tensiona el tipo de políticas migratorias o de extranjería que existen en determinados países.

Chile representó para algunos un imaginario de prosperidad, una ilusión, porque al momento de habitar en diferentes territorios del país o al interior de ciudades supuestamente ricas y altamente productivas, deben negociar y desplegar diferentes estrategias dada su condición de persona a similidad a "otro", "extranjero", "distinto". Todos coincidieron que Chile es un país clasista, racista y especulador. Desde la entrada al país todos debieron desarrollar estrategias de movilidad. Frente a esto todos tuvieron que construir trayectorias azarosas al interior del país. Todas (os) negociaron el acceso al suelo, a la vivienda, el ingreso a una población, a una vivienda, aunque la condición de ahorro de dos sujetos venezolanos les permite habitar en lugares con condiciones más dignas.

Pese a lo anterior, todos están dominados por la ilusión de habitar un territorio relativamente rico, extractivo pero inequitativo. Todas y todos han tenido que negociar algo. Los aquí entrevistados se ven enfrentados, además, a un Estado neoliberal que aumenta sus riesgos sociales. No existe para ellos, indistintamente su trayectoria, un Estado de derecho que sea "guardián del orden público" (Castel, 2013, p. 24) o que sea garante de derechos y bienes colectivos e individuales. Es aquí donde la nueva política migratoria chilena debe poner el acento: cómo dar garantías de que todas las personas en su condición de seres humanos sean garantes de derechos básicos como el buen vivir, el acceso a una vivienda, a salud y educación. Asimismo, la nueva política migratoria debe ahondar en la condición de refugio que exigen muchos sujetos y sus familias. También, se debe cuestionar qué significa ser ciudadano, si varios (as) de los y las entrevistadas tienen carnet de identidad, pero se sienten encarcelados en un sistema que los relega de derechos universales.

A partir de estos hallazgos, resulta interesante continuar profundizando en las posibles diferencias entre trayectorias migratorias y las relaciones que los países dentro de la región latinoamericana, Andina y del Caribe deben establecer. La economía y las condiciones sociales y políticas de nuestros países están en crisis, por lo tanto, cualquiera de nosotros puede ser tratado como un inmigrante, un no sujeto de derecho. Apelar a la solidaridad territorial evitaría escribir sobre trayectorias develadoras de violencias y racismos. Conjuntamente detrás de las tres tipologías se pone en cuestión cómo las propias sociedades de origen son racistas y limitan la movilidad de los sujetos. Cómo países fronterizos son racistas y clasistas y selectivos en quiénes pueden o no transitar, cómo un país demarca un norte blanco y un sur negro, un oriente rico, un poniente pobre. El territorializar la política migratoria comprendiendo la diversidad de los territorios y de las comunidades que la integran debe salir del papel y convertirse en práctica.

\section{Referencias bibliográficas}

ACNUR. (2012). Situación Colombia. Afrodescendientes. Recuperado de https://www.acnur.org/fileadmin/ Documentos/RefugiadosAmericas/Colombia/2013/ SituacionColombia_Afrodescendientes_junio2012. pdf?view $=1$

Amnistía Internacional. (2008). ¡Déjennos en paz! La población civil, víctima del conflicto armado interno de Colombia. Madrid: Amnistía Internacional.

Arboleda, M. (2018). Extracción en movimiento: circulación del capital, poder estatal y urbanización logística en el norte minero de Chile. Investigaciones Geográficas, 56, 3-26. https://doi.org/10.5354/07195370.2018 .48475

Authier, J., Bonvalet, C. \& Levy, J. (2010). Élire Domicile. La construction sociale des choix résidentiels. Lyon: Presses universitaires de Lyon.

Beck, U. (2007). Cómo los vecinos se convierten en judíos. La construcción política del extraño en una era de modernidad reflexiva. Papers, 84, 47-66. https://doi.org/10.5565/rev/papers/v84n0.1632

Boado, M. (1996). Movilidad ocupacional y mercado de trabajo: las caras ocultas del empleo urbano en Montevideo. Revista de Ciencias Sociales, 12, 1-14. 
Castel, R. (2013). La inseguridad social. ¿Qué es estar protegido? Buenos Aires: Ediciones Manantial SR.

Christensen, K. (2017). Life Trajectories of Migrant Care Workers in the Long-Term Care Sectors in Norway and the UK. Social Policy and Society, 16, 635-644. https://doi.org/10.1017/S1474746417000252

Contreras, Y., Neville, L.\& González, R. (2019). Housing In formality in access to housing for Latin American migrants a case study of an intermediate Chilean city. International Journal of Housing Policy, 19(3), 411-435. https://doi.org/10.1080/194 91247.2019 .1627841

Departamento de Extranjería [DEM].(2019). Migración en Chile. Recuperado de http//www.dem.cl

Duvivier, E. (2010). Entre installation et poursuite de la mobilité. Migrations Société, 3-4 (129-130), 243256. https://doi.org/10.3917/migra.129.0243

Fanon, F. (1973). Piel negra. Máscaras blancas. Buenos Aires: Abraxas.

Fomina, J. \& Frelak, J. (2008). Next Stopski London: Public Perceptions of Labour Migration Within the EU. The Case of Polish Labour Migrants in the British Press. London: Warsaw: Institute of Public Affairs.

Grafmeyer, Y. (2010). Approches sociologiques des choix résidentiels. En J. Authier, C., Bonvalet, C. \& Levy, J. Élire Domicile. La construction sociale des choix résidentiels (pp. 35-52). Lyon, Francia: Presses universitaires de Lyon.

Human rights watch [HRW]. (2018). Colombia, eventos de 2018. Recuperado de https://www.hrw.org/es/ world-report/2019/country-chapters/326041

Instituto Nacional de Estadísticas [INE]. (2019). Recuperado de http//www.ine.cl

Jiménez, M. (2009). Tendencias y hallazgos en los estudios de trayectoria: una opción metodológica para clasificar el desarrollo laboral. Revista electrónica de investigación educativa, 11(1), 1-21.

Mateo, C. \& Ledezma, T. (2006). Los venezolanos como emigrantes. Estudio exploratorio en España. Revista venezolana de análisis de coyuntura, 12(2),
245-267. Recuperado de https://www.redalyc.org/ pdf/364/36412214.pdf

Oslender, U. (2004). Geografías de terror y desplazamiento forzado en el Pacífico colombiano: conceptualizando el problema y buscando respuestas. En E. Restrepo, \& A. Rojas, Conflicto e (in)visibilidad. Retos en los estudios de la gente negra en Colombia (pp. 35-52). Popayán: Universidad del Cauca.

Restrepo, E. \& Rojas, A. (. (2004). Conflicto e in(visibilidad). Retos en los estudios de la gentre negra en Colombia. Popayán: Universidad del Cauca.

Rodríguez, C., Alfonso, T. \& Cavelier, I. (2008). El derecho a no ser discriminado. Primer informe sobre discriminación racial y derechos de la población afrocolombiana (versión resumida). Bogotá: Universidad de los Andes.

Ruiz, C. (2006). El triste macondo dominicano y la problemática dominico-haitiana. Santo Domingo: Editora Búho.

Salgado, F., Contreras, C. \& Albornoz, L. (2017). La migración venezolana en Santiago de Chile: entre la inseguridad laboral y la discriminación. Revista Internacional de Estudios Migratorios RIEM, 8(1), 81-117. https://doi.org/10.25115/riem.v8i1.2164

Sassen, S. (2003). Los espectros de la globalización. Buenos Aires: Fondo de Cultura Económica de Argentina.

Sassone, S. (2007). Migración, territorio e identidad cultural: construcción de "lugares bolivianos" en la Ciudad de Buenos de Buenos Aires. Población de Buenos Aires, 4(6), 9-28.

Sassone, S. \& Lapenda, M. (2019). Migración, territorio $\mathrm{y}$ transnacionalismo. Peruanos en una ciudad global del Sur. Cahiers des Amériques Latines, 91, 111-133. https://doi.org/10.4000/cal.9508

Segato, R. (2016). La guerra contra las mujeres. Madrid: Traficantes de sueños.

Spaccapietra, S., Parent, C., Damiani, M.L., Macedo, J.A., Porto, F. \& Vangenot, C. (2008). A conceptual view on trajectories. Data \& knowledge engineering, 65(1), 126-146. $\quad$ https://doi.org/10.1016/j. datak.2007.10.008 
Tijoux, M. \& Palominos, S. (2015). Aproximaciones teóricas para el estudio de procesos de racialización y sexualización en los fenómenos migratorios de Chile. POLIS, Revista Latinoamericana, 14(42), 247-275. https://doi.org/10.4067/S0718-65682015000300012

Tijoux, M. \& Córdova, G. (2015). Racismo en Chile: colonialismo, nacionalismo, capitalismo. POLIS, Revista Latinoamericana, 14 (42), 7-13. https://doi. org/10.4067/S0718-65682015000300001

Vargas, R. (2000). Trayectoria profesional de los ingenieros en la industria maquiladora electrónica: el caso de Sanyo Video componentes. Revista Electrónica de Investigación Educativa, 2 (2). Recuperado de http://redie.ens.uabc.mx/vol2no2/ contenido-vargas.html

Vasey, H. (2015). Trajectories of migration, social networks and emergent landscapes of migrant work. Migration Studies Advance Access, 4(1), 76-96. https://doi.org/10.1093/migration/mnv017 